\title{
The influence of personal characteristics and social support regarding pacifier introduction among preterm infants
}

\author{
Elaine Cristina Vargas Dadalto ${ }^{*}$ and Edinete Maria Rosa
}

\begin{abstract}
The study evaluated mothers of preterm infants who were discharged from the neonatal intensive care unit (NICU) with regard to their personal characteristics and those of their infants as well as the role that social support plays in deciding whether to introduce a pacifier during the first two years of the infant's life. This longitudinal study was based on the Bioecological Theory of Human Development. The mothers were interviewed at the NICU and when their infants were $6,12,18$, and 24 months old. The participants were grouped according to whether the infants used a pacifier (Group-A) or not (Group-B). The results showed that calm/peaceful maternal characteristics were more frequent in Group-A (75 \%), and nervous/agitated/irritated in Group-B (61.5\%; $p=0.041)$. Calm/easy-to-care/ independent infant characteristics prevailed in Group-A (55 \%), whereas agitated/messy/stubborn/aggressive characteristics did so in Group-B (84.6\%; $p=0.026)$. These latter traits were also associated with multiple offers for a pacifier $(p=0.006)$. Group-A reported one or two people in their social support network $(77.8 \%)$, whereas Group-B reported three to seven people $(66.7 \% ; p=0.001)$. In conclusion, calm/peaceful and calm/easy-to-care/independent characteristics predominated in the mothers and infants of Group-A; these infant traits were associated with easier pacifier acceptance. The extent of social support was significantly smaller in Group-A.
\end{abstract}

Keywords: Premature, Infants, Pacifiers, Human development, Social support

\section{Background}

Infants obtain their essential nutrition through breastfeeding (BF); at the same time, they experience other, non-nutritional sensations related to sucking on the breast, such as pleasure and safety. When the need for non-nutritive sucking is not completely satisfied, infants might become restless, cry, sleep little, or begin sucking on their hands and fingers (Camargo 2005). When trying to comfort infants, mothers or other family members might introduce pacifiers; this action can condition excessive offers, even among infants who would not typically suck their fingers. Thus, pacifier use might be a way of masking other infant needs. These infants also express themselves through crying, indicating indiscriminate offer (Albuquerque et al. 2010; Mendes et al. 2008; Oliveira et al. 2006; Peres et al. 2007; Serra-Negra et al. 1997).

Pacifiers are an interesting research subject because of their controversial status; they may or may not be a healthy

\footnotetext{
* Correspondence: elainedadalto@gmail.com

Universidade Federal do Espírito Santo, Vitória, Brazil
}

way of addressing the needs of a child (Selmer-Olsen 2007). Currently, the debate surrounding pacifiers continues. Some studies have recommended pacifiers, suggesting an association between their use and a decreased risk of sudden infant death syndrome (Mitchell et al. 2006). Furthermore, pacifiers can be used to stimulate nonnutritive sucking in preterm newborns (PNs) with or without musical sounds (Poore et al. 2008; Yildiz and Arikan 2011) and for pain relief during invasive procedures performed in hospitalized PNs (Yilmaz and Arikan 2011). In contrast, other studies have radically contrary conclusions regarding the introduction of pacifiers because they might interfere in BF, as the cause of early weaning (Soares et al. 2003). Pacifier use was also analysed as a consequence of the difficulties encountered by mothers to maintain $\mathrm{BF}$ as source of satisfaction of their infants' non-nutritive sucking urge; moreover, pacifiers' prolonged use has been correlated with the development of myofunctional and dental disorders (Verrastro et al. 2006; Oliveira et al. 2006; Peres et al. 2007; Mendes et al. 2008). 
Preliminarily, what can be observed from the research in this area is the presence of an adult, either the mother or another person, who could influence the mother-infant relationship through pacifier offer. Mauch et al. (2012) found that individuals from the mothers' social support advised that a pacifier should be introduced in $69.4 \%$ of all cases. The same researchers indicated that the major reasons for advising for pacifier use included calming the infant (78.3 \%), helping the infant fall asleep (57.4\%), keeping them comfortable and quiet (40.4\%), preventing finger sucking (20.9\%), regulating the time between feedings (12.6\%), helping the infant during tooth eruption (9.4\%), and facilitating removing the infant from the breast after feeding (6.8\%).

Araújo and Aiello (2013) found that most of the people who acted as sources of social support were family members of the mothers. Morgado et al. (2013) analysed social support for $\mathrm{BF}$ and demonstrated positive interference in the BF process such that mothers with more relatives in their social network were more likely to employ BF exclusively. In contrast, Marques et al. (2010) found that mothers' social networks functioned both as a support and as potential conflicts with regard to lactation. Moreover, Falceto (2002) demonstrated that $83 \%$ of mothers were able to depend on two or more individuals when needed; however, only effective BF support from the father directly protected the infant against early weaning. Falceto (2002) also suggests that in the specific case of PNs who require hospitalization in the neonatal intensive care unit (NICU), the quality of the mother's relationship with healthcare professionals as well as effective interactions between mothers and these professionals tends to foster the perception of effective hospital support among lactating mothers. This perception is essential for establishing BF (Müller and Silva 2009). Roseiro et al. (2013) also analysed these interactions as a humane care strategy in the NICU.

The design of the present study followed the precepts of the Bioecological Theory of Human Development (BTHD) to assess the complex factors related to the interactions between mothers and their preterm infants with regard to whether to introduce a pacifier, as well as the influence of individuals who provide direct social support to the mother. The BTHD consists of four components and the relationships among them, which form the process-person-context-time (PPCT) model. Process is defined as the interaction between developing humans and the people, objects, and symbols in their environment. This theory considers the proximal processes (PPs) as the primary mechanism that produces development. The influential power of the PPs depends on the characteristics of the person, their immediate and more remote environmental context, and the time periods in which these processes operate. To be effective, PPs should occur regularly, with progressive complexity and over prolonged periods of time (Bronfenbrenner and Morris 2006).

Children's psychological development is driven by their involvement in PPs with one or more individuals who are committed to their development and well-being (especially their parents), with whom they establish a mutual, permanent emotional attachment. It is an interactive process on two levels: Not only does the adult influence the behaviour of the infant, but he or she also influences the behavior of the adult. Actually, it is the infant who instigates the process in terms of energy and meaning (Bronfenbrenner 2001).

An individual's characteristics can influence development through their capacity to affect PPs as well as stimulate or block its action; furthermore, they might also appear as a result of the development represented by the characteristics that emerge throughout life (Bronfenbrenner and Morris 2006). When the research environment contains more than two individuals, analytical models must account for the indirect influence of the third person whose belief system can stimulate or maintain the reciprocal interaction with the developing person (Bronfenbrenner 2001).

Context is represented across four levels: the microsystem (i.e., the immediate environment where activities and interpersonal relationships occur face-to-face); the mesosystem (i.e., the set of microsystems in which the person participates directly); the exosystem (i.e., the influences from environments in which the person does not participate directly; and the macrosystem (i.e., the values and beliefs present in a common social organisation within a certain culture that can influence the relationship and the organisation of microsystems) (Bronfenbrenner 1994, 1995). The time dimension is presented across three levels: microtime, which is related to episodes at the PP level; mesotime, which is related to the frequency of these episodes over days and weeks; and macrotime, which is related to social expectations and events across generations (Bronfenbrenner and Morris 2006).

An individual's development can be influenced by the biological and social changes that occur throughout life. These changes often occur in more than one environment with reciprocal processes within these environments. Thus, this study evaluated mothers of preterm infants who were discharged from the NICU with regard to their personal characteristics and those of their infants as well as the role that social support plays in deciding whether to introduce a pacifier during the first 2 years of the infant's life.

\section{Methods}

\section{Participants}

The present study was conducted in a Brazilian city over 2 years. The participants were mothers of PNs (i.e., those 
with a gestational age [GA] less than 37 weeks) admitted to NICUs. One NICU was located in a public hospital and the other in a private hospital. Both units delivered similar levels of medical care and breastfeeding support during hospitalization.

\section{Procedure}

All the mothers of PNs were requested to take part in the first phase of this study. When their infants were 6 months old, the same mothers were invited to participate in an interview during the dental care of their children. Subsequent, successive assessments occurred at 12,18 , and 24 months based on the age of their children at the data collection points. Individual appointments were scheduled on the best day and time for participants.

The Ethics Committee of Research at the Centre for Health Sciences approved this project under No. 249/10. The participants signed a "Statement of Free and Informed Consent" in accordance with Resolution 196/96 of the National Health Council. This consent document included all time points of the study.

\section{Instrument}

Sociodemographic data were collected during the initial interview at the NICU. An interview script developed by the authors of this study was used for the subsequent phases $(6,12,18$ and 24 months). This instrument was previously tested and redeveloped. It was noticed that the questions were of easy understanding, resulting in minimal changes and the removal of a repetitive item. This script contained 55 closed- and 8 open-ended questions concerning the mother's general health, personal characteristics, feeding, infant habits, and social support. The research design was based on the BTHD; its main construct was represented by the PPs, which considered the interdependence of the elements of the PPCT model (Bronfenbrenner 2001). The present study analysed aspects related to the personal characteristics of the mothers and their infants over the 24-month follow-up period, the social support that they received throughout the first year of their infants' lives, and the pacifier sucking habit including offer attempts and reasons for pacifier introduction (all of which involve the influence of the mother-infant interaction). The mother' social support was analysed only in the first year because this time is the most exhausting to the mothers, regarding the demand in infant's care.

The mother's education was divided into the following categories based on whether a particular level of the Brazilian educational system was completed: incomplete primary education (IPE), complete primary education (CPE), incomplete secondary education (ISE), complete secondary education (CSE), incomplete higher education
(IHE), and complete higher education (CHE). Economic classification distributions were made according to the Brazilian economic classification criteria (Associação Brasileira de Empresas de Pesquisa ABEP 2010) and segmented from high to low purchasing power using the following classes: A1, A2, B1, B2, C1, C2, D, and E.

\section{Data analysis}

The interviews were recorded using an audio recorder and then transcribed and numbered. The open-ended questions were categorised using a semantic approach based on content analysis (Bardin 1977) so that the categories created based on the responses of the participants were associated with the inferred knowledge related to the messages produced. The first author analysed the interviews, and the second author compared the open-ended questions to obtain agreement in the categorisation process. The responses were tabulated using SPSS version 18.0 for Windows (SPSS Inc., Chicago, IL, USA) and presented using descriptive statistics.

The participants were grouped to analyse the data regarding pacifier use or not. Pacifier use was defined as a regular pacifier sucking habit. The failed attempts to introduce the infant a pacifier were not considered a pacifier use. Group A included participants whose children had used or were still using pacifiers; Group B included participants whose children had never used a pacifier as a habit. Data regarding participants' perceptions of their personal characteristics and those of their infants and with regard to social support were compared using the chi-square test or Fisher's exact test* (when the exposure variable involved two categories) or the Likelihood ratio ${ }^{* * * *}$ (when the exposure variable involved more than two categories) to verify the relationship between these characteristics and the use of a pacifier (Field 2009).

\section{Results}

The initial sample included 62 mothers of PNs admitted to public and private NICUs. At 6 months, 52 mothers attended the invitation to participate in this study, at 12 months 47 mothers, at 18 months 37 participants and at 24 months 33 participants. The data collected in this study comprised 33 mothers who attended all phases, corresponding to $53.2 \%$ of the initial group. No significant differences were found between the characteristics of participants who remained in the study $(n=33)$ and those who dropped out. The following categorical variables were independent of sample attrition: type of NICU, if public or private $\left(p=0.474^{*}\right)$, infant gender $\left(p=0.594^{*}\right)$, GA $\left(p=0.474^{*}\right)$, the duration of orogastric tube use $\left(p=0.450^{*}\right)$, primiparity $(p=0.582 *)$, economic classification $\left(p=0.570^{*}\right)$, city of residence $\left(p=0.296^{* * *}\right)$, employment $(p=0.636)$, and maternal education $(p=0.996)$.

Of the mothers of the preterm infants (whose characteristics are shown in Table 1) who completed all phases 
Table 1 Participants' description during the initial and final phases of the longitudinal study

\begin{tabular}{|c|c|c|}
\hline & $\begin{array}{l}\text { Initial phase } \\
n(\%)\end{array}$ & $\begin{array}{l}\text { Final phase } \\
n(\%)\end{array}$ \\
\hline \multicolumn{3}{|l|}{ Education level } \\
\hline IPE, CPE ISE & $14(42.4)$ & $13(39.4)$ \\
\hline CSE & $9(27.3)$ & $8(24.2)$ \\
\hline $\mathrm{IHE}, \mathrm{CHE}$ & $10(30.3)$ & $12(36.4)$ \\
\hline Attended complementary courses & - & $6(18.2)$ \\
\hline \multicolumn{3}{|l|}{ Number of children } \\
\hline 1 & $18(54.6)$ & $16(48.5)$ \\
\hline 2 & $11(33.3)$ & $13(39.5)$ \\
\hline 3 or 4 & $3(9.1)$ & $2(6.0)$ \\
\hline 5 or $5+$ & $1(3.0)$ & $2(6.0)$ \\
\hline \multicolumn{3}{|l|}{ Employment } \\
\hline Yes/Yes & $13(39.4)$ & $13(39.4)$ \\
\hline Yes/No & $6(18.2)$ & - \\
\hline No/Yes & - & $5(15.1)$ \\
\hline Stable union and lives with the infant's father & $27(81.8)$ & $26(78.8)$ \\
\hline Other individuals live in the same home & $7(21.2)$ & $5(15.2)$ \\
\hline
\end{tabular}

IPE incomplete primary education, CPE complete primary education, ISE incomplete secondary education; CSE complete secondary education, IHE incomplete higher education, CHE complete higher education

of the longitudinal study, the most frequently reported changes in their general health were hypertension, anemia, urinary tract infection, headache, and gastro esophageal reflux.

Of the 33 newborn infants, $48.5 \%$ were male and $51.5 \%$ female; $33.3 \%$ had a GA of less than 34 weeks, and $66.7 \%$ of them a GA between 34 and 37 weeks. There were no statistically significant difference between these characteristics of Groups A and B ( $p=0.284^{*}$ and $\left.p=0.435^{* *}\right)$. A total of $81.8 \%$ of the infants had birth weights less than 2,500 g; moreover, $45.5 \%$ were admitted to public NICU, and $54.5 \%$ were admitted to private NICU. A total of $84.8 \%$ of infants were hospitalized for more than 7 days $($ mean $=29.15 ; S D=26.87)$, and $90.9 \%$ were fed via an orogastric tube. At the end of the 2-year follow-up assessment, $51.5 \%$ of the mothers reported that their infants were in good health, the most common complaints being asthma, pneumonia, gastro esophageal reflux, and viral infection. A total of $84.8 \%$ of the mothers reported that their infants' weights, heights, and development were consistent with the chronological ages of their infants; only $15.2 \%$ reported delays in these variables, and $30.3 \%$ required therapy or targeted stimulation.

In the 6-month interview, of the 33 participants it was observed that 32 attempted to give their infants a pacifier at some point; 15 mothers only offered the pacifier once to determine whether the infant wanted it, and 17 mothers made several attempts, for about three to seven days. However, some attempts of pacifier offer had failed, therefore the pacifier sucking habit was observed in 18 infants at the 6- and 12-month time points composing the Group A, while in Group B there were 15 participants. It was noticed that between the 12- and 18-month time points, there was a new attempt of pacifier offer in two cases and these infants started using the pacifier. Thus, at the 18- and 24-month time points, there were 20 participants in Group A and 13 in Group B.

The personal characteristics of the mothers and the changes they observed over the 2-year study were organized into seven categories: (a) as calm/peaceful as before the infant's birth $(n=14,42.4 \%)$; (b) more calm/ peaceful than before the infant's birth $(n=2,6.1 \%)$; (c) as nervous/agitated/irritated as before the infant's birth $(n=3,9.1 \%)$; (d) more nervous/agitated/irritated than before the infant's birth $(n=4,12.1 \%)$; (e) formerly calm/peaceful before the infant's birth but nervous/agitated/irritated after the infant's birth $(n=6,18.2 \%)$; (f) formerly nervous/agitated/irritated before the infant's birth but calm/peaceful after the infant's birth $(n=3$, $9.1 \%)$; and (g) formerly calm/peaceful before the infant's birth, then nervous/agitated/irritated after the infant's birth, and then eventually calm/peaceful $(n=1,3.0 \%)$. Maternal characteristics at the end of the study were not related to the number of times that the pacifier was offered $(p=0.602 *)$. Comparing the groups (Table 2) calm/ peaceful mothers predominated in Group A (infants using pacifiers), and nervous/agitated/irritated mothers predominated in Group B (no pacifier use).

Most mothers described their infants' characteristics at 6 months as calm/peaceful (78.8\%). This percentage reduced to $54.6 \%$ by 12 months, and $24.2 \%$ described their infants as agitated/messy; others reported that their infants were prone to stubbornness and tantrums (21.2 \%). At 18 months, $27.2 \%$ of mothers classified their infants as calm/peaceful, $21.2 \%$ as agitated/messy, $42.5 \%$ as stubborn, and $9.1 \%$ as aggressive (e.g., pushing, hitting, or

Table 2 Self-reported characteristics of the mothers and their infants at the end of the study with regard to the use of pacifiers over a 2-year follow-up

\begin{tabular}{llllllll}
\hline Characteristics at the end of the study & \multicolumn{4}{l}{ Pacifier use } & & \\
\cline { 2 - 5 } & & Group A & Group B & \\
\cline { 2 - 5 } & $n$ & $\%$ & $n$ & $\%$ & \\
\hline Categories attributed to the mother & & & & & \\
Calm/peaceful & 15 & 75.0 & 5 & 38.5 & $0.041^{*}$ \\
$\quad$ Nervous/agitated/irritated & 5 & 25.0 & 8 & 61.5 & \\
Categories attributed to the infant & & & & & \\
$\quad$ Calm/easy to care/independent & 11 & 55.0 & 2 & 15.4 & $0.026^{*}$ \\
Agitated/messy/stubborn/aggressive & 9 & 45.0 & 11 & 84.6 & \\
Total & 20 & 100.0 & 13 & 100.0 & - \\
\hline
\end{tabular}

*Fisher's exact test 
biting). At 24 months, $27.2 \%$ of infants were described as calm/quiet, $21.2 \%$ as agitated/messy, $24.2 \%$ as stubborn, $15.2 \%$ as aggressive, and $9.1 \%$ as calm/peaceful, but stubbornness was described as occurring when the infants were upset, and $3.0 \%$ of mothers described their infants as independent/decisive nature. To statistically compare Groups A and B, the infants were grouped as easy to care for (e.g., calm, peaceful, and independent infants) or difficult to care for (e.g., agitated, messy, stubborn, or aggressive infants) based on the maternal evaluation at the end of the study (Table 2). The first category was more frequent in Group A, while the latter predominated in Group B $(p=0.026)$. Table 3 presents the mother-reported infant characteristics with regard to pacifier offer attempt.

In most cases, it was the mother who introduced a pacifier to their infant ( $n=13$ of $20 ; 65 \%)$. Their motivations for initiating pacifier use, reported at the 6-month interview, were to calm their infants and help them fall asleep; some mothers also reported that their infants cried excessively and were agitated prior to using a pacifier. Moreover, the motivations to introduce pacifiers after 6 months were related to mothers' returning to work (in these cases, the maternal grandmother introduced the pacifier) or based on the recommendation of day care providers who claimed that these children made multiple attempts to take pacifiers away from others.

The interactions between the mothers and infants also involved informal social support with the participation of individuals from the nuclear family, including the father, siblings over 8 years old, and other relatives, as well as neighbours, who supported the mother in childcare. Few participants reported that their infants only had contact with the nuclear family or day care. Of the 29 mothers who lived in the same home with their partners, paternal support was perceived in two ways: fathers who helped and were involved in infant care $(37.9 \%)$ and fathers who helped distract the infant, although they did not actually participate in other types of infant care (62.1\%).

At the 6- and 12-month interviews, $75.7 \%$ of mothers reported formal social support provided by an employee to look after the house and $27.3 \%$ a person to care for the infant; only one infant attended formal childcare.

Table 3 Characteristics attributed to the 24-month-olds at the end of the study based on pacifier offer attempt as assessed by their mothers

\begin{tabular}{|c|c|c|c|c|c|}
\hline \multirow[t]{3}{*}{ Characteristics attributed to the infant } & \multicolumn{4}{|c|}{ Pacifier offer attempt } & \multirow{3}{*}{$p$-value } \\
\hline & \multicolumn{2}{|c|}{ Once } & \multicolumn{2}{|c|}{ Several times } & \\
\hline & $n$ & $\%$ & $n$ & $\%$ & \\
\hline Calm/easy to care/independent & 10 & 66.7 & 3 & 17.6 & $0.006^{*}$ \\
\hline Agitated/messy/stubborn/aggressive & 5 & 33.3 & 14 & 82.4 & \\
\hline Total & 15 & 100.0 & 17 & 100.0 & - \\
\hline
\end{tabular}

*Fisher's exact test
Regarding the informal social support received at 6 and 12 months, mothers in Group A depended on one or two people to help care for their infant, whereas mothers in Group B depended on between three and seven people; only two participants in each group reported that they were not supported (Table 4).

The participation of individuals involved in the informal social support with regard to pacifier use was assessed for their ability to influence the mothers' decisions. In most cases, it was found that pacifier use was encouraged by grandparents, great-grandparents, and uncles (60\%), while in $30 \%$ of the 20 cases pacifier use was stimulated by mothers themselves and in $10 \%$ by fathers. Extended relatives became especially important when the mother returned to work and depended on them to care for their infant. In general, family members encouraged pacifier use and only $35 \%$ disagreed. Regarding finger sucking, however, at the 24 months followup, mothers and family members were observed to strongly discourage their infant from this sucking habit. Mothers in Group A removed the infants' fingers from their mouth and placed a pacifier or a teether in their mouth. Mothers in Group B used a teether or cloth for this purpose. At 18 months, $24.2 \%$ of infants attended day care; at 24 months, $42.4 \%$ did so.

\section{Discussion}

Most infants had low birth weights (fewer than 2,500 g), which might interfere with their development according to the BTHD (Bronfenbrenner and Morris 2006). During the follow-up assessment, however, participants reported the progress of their infants $(84.8 \%$ of whom were within the expected ranges for weight, height, and development based on their age) with joy.

The qualities used to characterize the mothers and their infants were analysed as participants perceived them over time. In many cases, mothers reported that they became more nervous, agitated or irritated after birth or became calmer as they learnt how to take care of their infant. According to Bronfenbrenner (2001), the children exert powerful influence on the behaviour and psychological

Table 4 The distribution of participants based on the number of individuals who were able to help care for the infant during the first year of life

\begin{tabular}{|c|c|c|c|c|c|}
\hline \multirow{3}{*}{$\begin{array}{l}\text { Number of support } \\
\text { individuals }\end{array}$} & \multicolumn{4}{|c|}{ Pacifier use at 12 months } & \multirow{3}{*}{$p$-value } \\
\hline & \multicolumn{2}{|c|}{ Group A } & \multicolumn{2}{|c|}{ Group B } & \\
\hline & $n$ & $\%$ & $n$ & $\%$ & \\
\hline None & 2 & 11.1 & 2 & 13.3 & $0.001^{* *}$ \\
\hline 1 or 2 individuals & 14 & 77.8 & 3 & 20.0 & \\
\hline 3 to 7 individuals & 2 & 11.1 & 10 & 66.7 & \\
\hline Total & 18 & 100.0 & 15 & 100.0 & - \\
\hline
\end{tabular}

**ikelihood ratio 
development of their parents, especially in the first years of life. This effect was observed in the present study when the mothers indicated a change in their personal characteristics after their infants' births. The mothers described their infants' characteristics based on attributes related to their current period of intense development; specifically, $78.8 \%$ of infants were described as peaceful at 6 months, $54.6 \%$ were described as peaceful at 12 months, and $27.2 \%$ were described as peaceful at 18 months and at 24 months. In contrast, the first reports of stubbornness $(21.2 \%)$ appeared at 12 months and increased at 18 months (42.5\%). This characteristic can be analysed as a negative emotional sub-dimension, which characterised by difficulties in controlling emotions, presents behaviours such as screaming or crying due to frustration (Seabra-Santos and Almeida 2014). It is necessary to draw attention to the importance of the early detection of individuals' characteristics that could influence the child's development as debated by Klein and Linhares (2007).

Reports of stubbornness decreased at 24 months (24.2 \%) when several mothers reported that they had learned to address this behaviour. This finding matches that of Feldman et al. (2011) who found that the presence of positive maternal behaviours promoting emotional self-regulation was related to the greater abilities to curb aggressiveness in 2- to 3-year-olds. Cassiano and Linhares (2015) also highlighted that the mother-infant interaction quality can influence the child's temperament, specially at an age considered a turning point to self-regulation and a higher demand for a more active maternal behavior. The present result implies that the establishment of progressively more complex PPs and mutual emotional attachments with the mother and the individuals committed to the development of the infant lead to the internalization of affection and the activities undertaken by the parents (Bronfenbrenner 2001).

Mother-described calm/easy-to-care-for/independent infant characteristics were common among children who had used or were still using a pacifier. This result and the reports about the motivation for offering a pacifier were consistent with those of other studies in which mothers justified introducing pacifiers to calm their infants (Mauch et al. 2012; Sertório and Silva 2005). However, considering the data regarding attempts to offer a pacifier, infants described by their mothers as calm/easy-to-care-for/independent at 24 months were more likely to have single pacifier offers. In contrast, most mothers who reported several pacifier-offer attempts had agitated/messy/stubborn/ aggressive infants. On this theme, Bronfenbrenner and Morris (2006) discussed the capacity of the biopsychological characteristics of the developing person to affect the direction and power of PP at a given stage of development, considering that PP encompass interaction not only with people but also with objects and symbols.
According to the BTHD, context is not only related to the physical conditions of the environment but also to how it is perceived by developing individuals and how they experience the subjectivity of this experience, thereby allowing positive and negative polarities to coexist to varying degrees regarding the experience. This issue, referenced by Bronfenbrenner (2001), can be analysed when considering the ambivalence shown by some mothers regarding the use of a pacifier for their children. Despite their assessment that pacifier use is not innocuous, they recognised that it helps to calm infants. Furthermore, the pacifier is considered by mothers as a way to calm the infant that can be easily removed compared with finger sucking because mothers and other family members intensely interfered to curb this behaviour by removing the fingers from the infants' mouth and offering pacifiers or teethers.

As for the informal social support received by the mothers, as an indirect influence on the effectiveness of PPs between mothers and infants, in $77.8 \%$ of the cases mothers in Group A reported that one or two individuals were able to help care for the infant during the first year of life, whereas $66.7 \%$ of the mothers in Group B reported three to seven people. This level of support was below that reported by Falceto (2002) in a study on early weaning (83\%), including two or more individuals. Social networks can operate under positive aspects in which the mother depends on more relatives and receives strong social support, thereby increasing the likelihood of a positive outcome, such as exclusive BF (Morgado et al. 2013). Marques et al. (2010) analysed both the positive and negative influences in which social networks functioned as a support but also as a generator of possible conflicts. With regard to mothers of PNs admitted to the NICU, the quality of the relationship with healthcare professionals and their perceived support is essential to establish BF (Müller and Silva 2009) and humanised service (Roseiro et al. 2013).

The belief system of the individuals in the microsystem or exosystem of the child might stimulate reciprocal interactions between mothers and their children. The direct action of the pacifier to help distract infants also has the effect of providing physical rest for mothers who start to feel able to be involved in lasting PPs with their children (Bronfenbrenner 1999). The establishment and maintenance of interaction patterns increasingly more complex depend, to some extent, on the availability and involvement of a third person (Bronfenbrenner 2001). Thus, the presence of the father, grandparents, and neighbours can influence the mother-child relationship by modifying its quality, intensity, duration, and complexity (Rosa and Tudge 2013).

In contrast, considering the cultural aspects involved in the offer of pacifiers, the family members in the present study generally encouraged their use; only a few discouraged their use. When the mothers returned to 
work and depended on other family members to care for the infant, these social supports were those most likely to encourage pacifier use, thereby enhancing the analysis of the cultural influences associated with offering this object (Selmer-Olsen 2007). As Mauch et al. (2012) demonstrated, mothers provided pacifiers $30.6 \%$ of the time, and grandparents did so $28.8 \%$ of the time. Specifically at day care, infants who did not use pacifiers were influenced by being with others who used them.

The present study has strengths such as the longitudinal assessment over 2 years; however, certain limitations should be noted. The small number of participants and the lack of a probabilistic sample limit the generalisability of the results; thus, additional studies should assess the characteristics of mothers and their infants, and their social support regarding the use of pacifiers. Future studies should also examine full-term infants.

\section{Conclusions}

The characteristics attributed to the mothers were categorised into two major groups: calm/peaceful and nervous/agitated/irritated. Based on interactions with their children, participants perceived changes in their characteristics over time, oscillating between these categories throughout the study. The mothers described themselves as calm/peaceful more often when their infants used pacifiers.

Maternal perceptions regarding their infants' characteristics reasserted the attributes related to their intense development period. Calm/easy-to-care-for/independent infants were more likely to use a pacifier; agitated/messy/stubborn/aggressive infants were more likely not to use pacifiers. However, the results regarding pacifier offering attempts showed that calm/easy-to-care-for/independent infants more easily accepted pacifiers than those described as agitated/messy/stubborn/aggressive who rejected pacifiers or accepted them after several offers.

Most mothers showed signs of ambivalence when they referred to the help provided by the pacifier to calm their infants, even though they were aware that it is not an innocuous habit. On the other hand, mothers and family members intensely interfered to prevent infants from placing their fingers in their mouths to discourage finger sucking.

Support from the infant's father was perceived by most mothers as a help to distract the infant, without direct involvement in care. Few reports have suggested that fathers neither encouraged nor discouraged pacifier use. The informal social support provided by family and neighbours during the first year of the infant's life has an indirect influence capable of undermining the effectiveness of the PPs between mother and infant. Mothers whose infants used pacifiers reported one or two individuals who were able to help care for the infant, whereas those whose infants did not use pacifiers depended on three to seven individuals; this difference was statistically significant. Moreover, even with fewer supports, these family members exerted influence by encouraging the use of pacifiers, and few discouraged, especially when the mothers returned to work and relied on family members to care for the infant. This analysis strengthens the cultural influence associated with a pacifier offer.

\section{Competing interests}

The authors declare that they have no competing interests.

\section{Authors' contributions}

ECVD participated in the study design, data collection, analysis and interpretation of data. EMR participated in the study design, data interpretation and critical content review. All authors read and approved the final manuscript.

Received: 15 March 2016 Accepted: 7 April 2016

Published online: 14 April 2016

\section{References}

Albuquerque SSL, Duarte RC, Cavalcanti AL, Beltrão EM. A influência do padrão de aleitamento no desenvolvimento de hábitos de sucção não nutritivos na primeira infância [The influence of feeding methods in the development of non-nutritive sucking habits in childhood]. Ciên Saúde Colet. 2010;15(2):371-8.

Araújo GMS, Aiello ALR. Rede social de apoio de mães com deficiência intelectual [Social support networks for mothers with intellectual disabilities]. Psicol Reflexão e Crítica. 2013;26(4):752-61.

Associação Brasileira de Empresas de Pesquisa (ABEP). (2010). Critério de classificação econômica Brasil, 2010 [Brazilian economic classification criteria, 2010]. Available at: http://www.abep.org/criterio-brasil Accessed on: October 21, 2010

Bardin L. Análise de conteúdo [Content analysis]. Lisboa, Portugal: Edições 70; 1977. Bronfenbrenner U. Ecological models of human development. In: Husen T, Postlethwaite TN, editors. International Encyclopedia of Education. 2nd ed. Oxford, UK: Pergamon Press/Elsevier Science; 1994. p. 1643-7.

Bronfenbrenner $U$. Developmental ecology through space and time: A future perspective. In: Moen P, Elder Jr GH, Luscher K, editors. Examining lives in context: Perspectives on the ecology of human development. Washington, DC: American Psychological Association; 1995. p. 619-47.

Bronfenbrenner U. Environments in developmental perspective: Theoretical and operational models. In: Friedman SL, Wachs TD, editors. Measuring environment across the life span: Emerging methods and concepts. Washington, DC: American Psychological Association Press; 1999. p. 3-28.

Bronfenbrenner $U$. The bioecological theory of human development. In: Smelser NJ, Baltes PB, editors. International Encyclopaedia of the Social and Behavioural Sciences. Oxford, UK: Elsevier; 2001. p. 6963-70.

Bronfenbrenner U, Morris PA. The bioecological model of human development. In: Damon W, Lerner RM, editors. Handbook of child psychology: Theoretical models of human development. New York, NY: Wiley; 2006. p. 793-828.

Camargo MCF. Programa preventivo e interceptativo de maloclusões na primeira infância [Preventive and interceptive programme of malocclusions during early childhood]. In: Corrêa MSNP, editor. Odontopediatria na primeira infância. 2nd ed. São Paulo, Brasil: Santos; 2005. p. 171-2.

Cassiano RGM, Linhares MBM. Temperamento, prematuridade e comportamento interativo mãe-criança. Psicologia Reflexão e Crítica. 2015;28(2):416-24.

Falceto OG. A influência de fatores psicossociais na interrupção precoce do aleitamento materno [The influence of psychosocial factors on the early discontinuation of breastfeeding]. 2002, Tese (Doutorado em Clínica Médica). Porto Alegre: Faculdade de Medicina, Universidade Federal do Rio Grande do Sul; 2002

Feldman R, Dollberg D, Nadam R. The expression and regulation of anger in toddlers: Relations to maternal behaviour and mental representations. Infant Behav Dev. 2011;34(2):310-20.

Field A. Descobrindo a estatística usando o SPSS [Discovering statistics using SPSS]. 2nd ed. Porto Alegre, Brasil: Artmed; 2009. p. 606-39.

Klein VC, Linhares MBM. Temperamento, comportamento e experiência dolorosa na trajetória de desenvolvimento da criança. Paideia. 2007;17(36):33-44. 
Marques ES, Cotta RMM, Botelho MIV, Franceschini SCC, Araújo RMA, Lopes LL. Rede social: desvendando a teia de relações interpessoais da nutriz [Social network: Revealing the social affairs of the nursing mother]. Physis Rev Saúde Colet. 2010;20(1):261-81.

Mauch CE, Scott JA, Magarey AM, Daniels LA. Predictors of and reasons for pacifier use in first-time mothers: an observational study. BMC Paediatr. 2012;12(7):1-10

Mendes ACR, Valença AMG, Lima CM. Associação entre aleitamento, hábitos de sucção não nutritivos e maloclusões em crianças de 3 a 5 anos [The relationship between maternal breastfeeding and non-nutritive sucking habits]. Ciênc Odontol Bras. 2008;1(1):67-75.

Mitchell EA, Blair PS, L'Hoir MP. Should pacifiers be recommended to prevent sudden infant death syndrome? Pediatrics. 2006;117(5):1755-8.

Morgado CMC, Werneck GL, Hasselmann MH. Rede e apoio social e práticas alimentares de crianças no quarto mês de vida [Social networks, social support, and the feeding habits of infants in their fourth month of life]. Ciênc Saúde Colet. 2013;18(2):367-76.

Müller FS, Silva IA. Representações sociais de um grupo de mulheres/nutrizes sobre o apoio à amamentação [Social representations regarding support for breastfeeding in a group of breastfeeding women]. Rev Lat Am Enfermagem. 2009; 17(5):651-57.

Oliveira AB, Souza FP, Chiappetta ALML. Relação entre hábitos de sucção nãonutritiva, tipo de aleitamento e má oclusão em crianças com dentição decídua The relationship between non-nutritive sucking habits, infant feeding methods, and malocclusion among children with primary dentition]. Rev CEFAC. 2006:8(3):352-9.

Peres KG, De Oliveira Latorre Mdo R, Sheiham A, Peres MA, Victora CG, Barros FC. Social and biological early influences on the prevalence of open bite in Brazilian 6-year-olds. International Journal of Paediatric Dentistry. 2007;17(1):41-9.

Poore M, Zimmerman E, Barlow SM, Wang J, Gu F. Patterned orocutaneous therapy improves sucking and oral feeding in preterm infants. Acta Paediatr. 2008;97(7):920-7.

Rosa EM, Tudge J. Urie Bronfenbrenner's theory of human development: Its evolution from ecology to bioecology. J Fam Theory Rev. 2013;5(4):243-58.

Roseiro CP, Paula KM, De P. Humanização em UTI neonatal: conjugando os aspectos tecnológicos e relacionais na assistência integral ao bebê e sua família [Humanisation of the neonatal ICU: Combining technological and relational aspects in the integral care of the infant and their families]. In: Garcia A, Macedo TA, Nunes MDC, editors. Relações Interpessoais e Saúde. 1st ed. Vitória, Brasil: UFES; 2013. p. 107.

Seabra-Santos MJ, Almeida MS. Falamos da mesma criança? Concordância mãe - pai - professores na avaliação do temperamento de crianças portuguesas [Is that the same child? Parents' and teachers' agreement in temperament assessments of Portuguese children]. Psicol Reflexão e Crítica. 2014;27(1):10-20.

Selmer-Olsen I. The pacifier: A story about comfort, rituals, and the aesthetification of childhood. Childhood. 2007;14(4):521-35.

Serra-Negra JMC, Pordeus IA, Rocha Jr JF. Estudo da associação entre aleitamento, hábitos bucais e maloclusões [A study of the relationships among infant feeding methods, oral habits, and malocclusion]. Rev Odontol Univ Sao Paulo. 1997;11(2):79-86.

Sertório SCM, Silva IA. As faces simbólica e utilitária da chupeta na visão de mães [The symbolic and utilitarian facets of pacifiers according to mothers]. Rev Saude Publica. 2005;39(2):156-62.

Soares ME, Giugliani ER, Braun ML, Salgado AC, Oliveira AP, Aguiar PR. Uso de chupeta e sua relação com o desmame precoce em população de crianças nascidas em Hospital Amigo da Criança [Pacifier use and its relationship with early weaning among infants born at a child-friendly hospital]. J Pediatr. 2003;79(4):309-16.

Verrastro AP, Stefani FM, Rodrigues CR, Wanderley MT. Occlusal and orofacial myofunctional evaluation in children with primary dentition, anterior open bite, and pacifier sucking habit. Int J Orofacial Myology. 2006;32:7-21.

Yildiz A, Arikan D. The effects of giving pacifiers to premature infants and making them listen to lullabies on their transition period for total oral feeding and sucking success. J Clin Nurs. 2011;21(5-6):644-56.

Yilmaz F, Arikan D. The effects of various interventions to newborns on pain and duration of crying. J Clin Nurs. 2011;20(7-8):1008-17.

\section{Submit your manuscript to a SpringerOpen ${ }^{\mathcal{O}}$ journal and benefit from:}

- Convenient online submission

- Rigorous peer review

- Immediate publication on acceptance

- Open access: articles freely available online

- High visibility within the field

- Retaining the copyright to your article

Submit your next manuscript at springeropen.com 